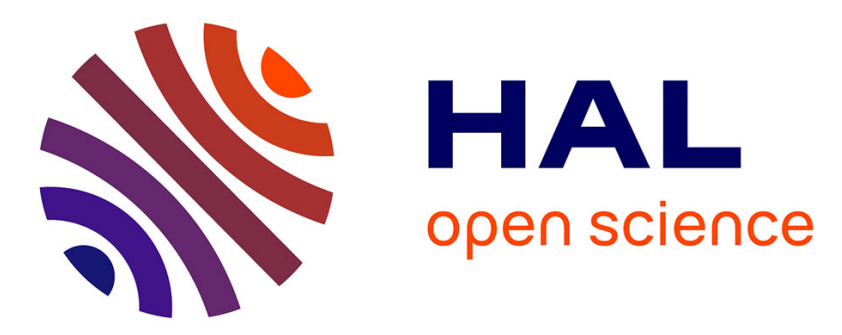

\title{
Substrate Effect on the High Temperature Oxidation Behavior of a Pt-modified Aluminide Coating. Part II: Long-term Cyclic-oxidation Tests at 1,050 C
}

\author{
Nadia Vialas, Daniel Monceau
}

\section{> To cite this version:}

Nadia Vialas, Daniel Monceau. Substrate Effect on the High Temperature Oxidation Behavior of a Pt-modified Aluminide Coating. Part II: Long-term Cyclic-oxidation Tests at 1,050 C. Oxidation of Metals, 2007, vol. 68, pp.223-242. 10.1007/s11085-007-9072-z . hal-00806046

\section{HAL Id: hal-00806046 https://hal.science/hal-00806046}

Submitted on 29 Mar 2013

HAL is a multi-disciplinary open access archive for the deposit and dissemination of scientific research documents, whether they are published or not. The documents may come from teaching and research institutions in France or abroad, or from public or private research centers.
L'archive ouverte pluridisciplinaire HAL, est destinée au dépôt et à la diffusion de documents scientifiques de niveau recherche, publiés ou non, émanant des établissements d'enseignement et de recherche français ou étrangers, des laboratoires publics ou privés. 


\section{OATAO \\ Open Archive Toulouse Archive Ouverte}

\section{Open Archive Toulouse Archive Ouverte (OATAO)}

OATAO is an open access repository that collects the work of Toulouse researchers and makes it freely available over the web where possible.

This is an author-deposited version published in: http://oatao.univ-toulouse.fr/ Eprints ID: 2401

To link to this article: doi: $10.1007 / \mathrm{s} 11085-007-9072-\mathrm{z}$

URL: http://dx.doi.org/10.1007/s11085-007-9072-z

To cite this version: Vialas, Nadia and Monceau, Daniel Substrate Effect on the High Temperature Oxidation Behavior of a Pt-modified Aluminide Coating. Part II: Long-term Cyclic-oxidation Tests at 1,050 C. (2007) Oxidation of Metals, vol. 68 ( $\mathrm{n}^{\circ} 5$ - 6). pp. 223-242. ISSN 0030-770X

Any correspondence concerning this service should be sent to the repository administrator: staff-oatao@ listes-diff.inp-toulouse.fr 


\title{
Substrate Effect on the High Temperature Oxidation Behavior of a Pt-modified Aluminide Coating. Part II: Long-term Cyclic-oxidation Tests at $1,050{ }^{\circ} \mathrm{C}$
}

\author{
Nadia Vialas · Daniel Monceau
}

\begin{abstract}
This second part of a two-part study is devoted to the effect of the substrate on the long-term, cyclic-oxidation behavior at $1,050{ }^{\circ} \mathrm{C}$ of RT22 industrial coating deposited on three Ni-base superalloys (CMSX-4, SCB, and IN792). Cyclicoxidation tests at $1,050{ }^{\circ} \mathrm{C}$ were performed for up to 58 cycles of $300 \mathrm{~h}$ (i.e., $17,400 \mathrm{~h}$ of heating at $1,050^{\circ} \mathrm{C}$ ). For such test conditions, interdiffusion between the coating and its substrate plays a larger role in the damage process of the system than during isothermal tests at $900,1,050$, and $1,150{ }^{\circ} \mathrm{C}$ for $100 \mathrm{~h}$ and cyclicoxidation tests at $900{ }^{\circ} \mathrm{C}$ which were reported in part I [N. Vialas and D. Monceau, Oxidation of Metals 66, 155 (2006)]. The results reported in the present paper show that interdiffusion has an important effect on long-term, cyclic-oxidation resistance, so that clear differences can be observed between different superalloys protected with the same aluminide coating. Net-mass-change (NMC) curves show the better cyclic-oxidation behavior of the RT22/IN792 system whereas uncoated CMSX-4 has the best cyclic-oxidation resistance among the three superalloys studied. The importance of the interactions between the superalloy substrate and its coating is then demonstrated. The effect of the substrate on cyclic-oxidation behavior is related to the extent of oxide scale spalling and to the evolution of microstructural features of the coatings tested. SEM examinations of coating surfaces and cross sections show that spalling on RT22/CMSX-4 and RT22/SCB was favored by the presence of deep voids localized at the coating/oxide interface. Some of these voids can act as nucleation sites for scale spallation. The formation of such interfacial voids was always observed when the $\beta$ to $\gamma^{\prime}$ transformation leads to the formation of a two-phase $\beta / \gamma^{\prime}$ layer in contact with the alumina scale. On the contrary, no voids were observed in RT22/IN792, since this $\beta$ to $\gamma^{\prime}$ transformation occurs gradually by an inward transformation of $\beta$ leading to the formation of a continuous layer of $\gamma^{\prime}$ phase, parallel to the metal/scale interface.
\end{abstract}

N. Vialas $\cdot$ D. Monceau $(\bowtie)$

CIRIMAT CNRS-INPT-UPS, ENSIACET, 31077 Toulouse Cedex 4, France

e-mail: Daniel.Monceau@ensiacet.fr 
Keywords Pt-modified aluminide coating · Ni-base superalloy ·

High temperature oxidation · Interdiffusion - Long-term cyclic-oxidation ·

Voids formation · Spallation

\section{Introduction}

In part I of this study, short-term, isothermal-oxidation tests at 900, 1,050, and $1,150{ }^{\circ} \mathrm{C}$ and long-term, cyclic-oxidation tests at $900{ }^{\circ} \mathrm{C}$ were performed on RT22 coatings deposited on three different Ni-base superalloys (CMSX-4, SCB, and IN792) [1]. This first part was focused on the influence of the substrate on the composition and microstructure of the Pt-modified-aluminide coating. The effect of alloying elements $\mathrm{Ti}$ and $\mathrm{Ta}$ was more particularly detailed. The three coating systems show excellent cyclic-oxidation behavior at $900{ }^{\circ} \mathrm{C}$. However, this temperature is not damaging enough to approach the end of the coating lifetime after 15,600 h. Therefore, this second part concerns long-term. Cyclic-oxidation tests performed at $1,050{ }^{\circ} \mathrm{C}$ for test durations up to $17,400 \mathrm{~h}$. At this temperature, interdiffusion between the coating and its substrate plays a large part in the damage process (overall $\mathrm{Al}$ consumption of the coating) and has a strong effect on cyclicoxidation resistance. Then, this test is discriminating between the several systems studied. Such long-term cyclic-oxidation at $1,050{ }^{\circ} \mathrm{C}$ permits discussion of the combined roles of selective oxidation, scale spallation and interdiffusion on $\mathrm{Al}$ consumption.

\section{Experimental Procedure}

The coating/substrate systems investigated in the present paper (i.e., RT22/CMSX4, RT22/SCB, and RT22/IN792) are described in part I, including a detailed characterization of their initial microstructure. RT22 is a high-activity, Pt-modified diffusion-aluminide coating. The compositions of the nickel base superalloys are given in Table 1. The long-term, cyclic-oxidation kinetics at $1,050{ }^{\circ} \mathrm{C}$ up to 58 cycles of $300 \mathrm{~h}$ (i.e., 17,400 h) were performed using the same experimental setup and procedures described in part I for the test at $900{ }^{\circ} \mathrm{C}$, in laboratory air. The duration of the high-temperature dwell is $300 \mathrm{~h}$. Samples are placed in a hot furnace and removed after the hot dwell to be placed in front of fans. Microstructural evolution of the specimens oxidized isothermally or after 6,17 , and 35 cycles was analyzed by SEM-EDX, XRD. RT22/CMSX4 was also analyzed by TEM on cross

Table 1 Nominal composition of CMSX-4, SCB, and IN792 substrates (at\%)

\begin{tabular}{lllrrrrrrrrrrr}
\hline at\% & $\mathrm{Ni}$ & $\mathrm{Cr}$ & $\mathrm{Co}$ & $\mathrm{Al}$ & $\mathrm{Ti}$ & $\mathrm{Ta}$ & $\mathrm{W}$ & $\mathrm{Mo}$ & $\mathrm{Re}$ & $\mathrm{Hf}$ & $\mathrm{Zr}$ & $\mathrm{Fe}$ & $\mathrm{Si}$ \\
\hline CMSX-4 & 63 & 7.5 & 10 & 12.6 & 1.3 & 2.2 & 2.1 & 0.3 & 1 & 0.03 & 0.00 & \\
SCB & 66 & 13 & 5 & 8.5 & 5.5 & 0.6 & 1.2 & 0.6 & & & & & \\
IN792 & 60.1 & 13.5 & 9 & 7.6 & 5 & 1.3 & 1.2 & 1.2 & & 0.2 & 0.1 & 0.5 & 0.4 \\
\hline
\end{tabular}


sections after 0,6 , and 17 cycles of $300 \mathrm{~h}$ at $1,050{ }^{\circ} \mathrm{C}$, and after $100 \mathrm{~h}$ at $1,050{ }^{\circ} \mathrm{C}$ (see part I for the sample preparation).

\section{Experimental Results}

\section{Cyclic-oxidation Kinetics at $1,050{ }^{\circ} \mathrm{C}$}

Cyclic-oxidation kinetics of each system were measured and are reported as NetMass-Change (NMC) curves in Figs. 1-3. The global shape of these curves results from the competition between mass gain caused by high-temperature oxidation and mass loss due to scale spallation. According to these NMC curves, RT22/IN792 appears to be the coating system most resistant to cyclic-oxidation.

Steady-state stages with almost constant negative slope are observed on NMC curves reported in Figs. 2, 3. During the steady-state stages, constant mass gain is due to oxidation at each high-temperature dwell and is followed by a constant mass loss caused by spallation during cooling. Nevertheless, several slope changes can be observed. These slope changes can be attributed to the formation of oxides other than $\mathrm{Al}_{2} \mathrm{O}_{3}$ such as $\mathrm{NiAl}_{2} \mathrm{O}_{4}$ spinel and/or $\mathrm{NiO}$ which were detected by XRD.

NMC curves for uncoated superalloys are also reported in Fig. 3. Mass losses were recorded even after the first cycle of $300 \mathrm{~h}$, indicating severe scale spallation on the three bare superalloys. This observation is a convincing demonstration of the efficiency of the coating studied in protecting superalloys against high temperature oxidation. Figure 3 also shows that CMSX-4 superalloy has better long-term oxidation behavior than the other two alloys. Indeed, the behaviors of the 3 Ni-base superalloys are similar before 10 cycles (i.e., 3,000 h), whereas after 12 cycles CMSX-4 alloy experiences much lower mass loss than the other alloys.

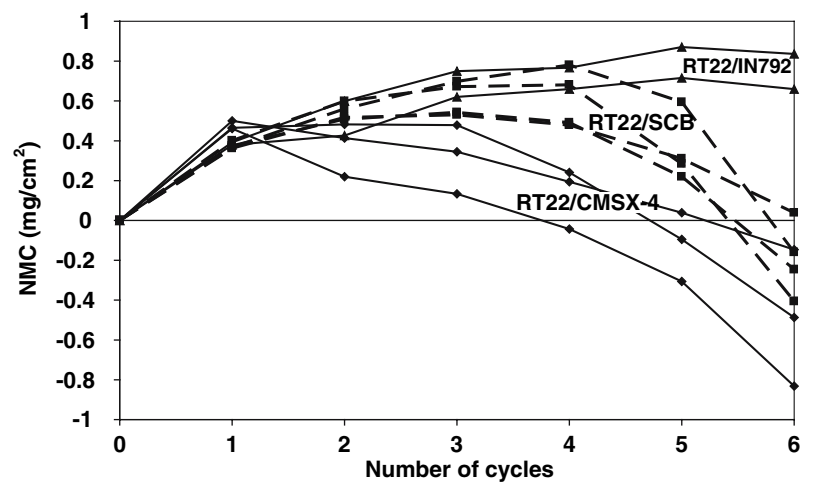

Fig. 1 Net mass change at $1,050{ }^{\circ} \mathrm{C}$ of several specimens of each system after 6 cycles of 300 h, i.e., $1,800 \mathrm{~h}$ in laboratory air 


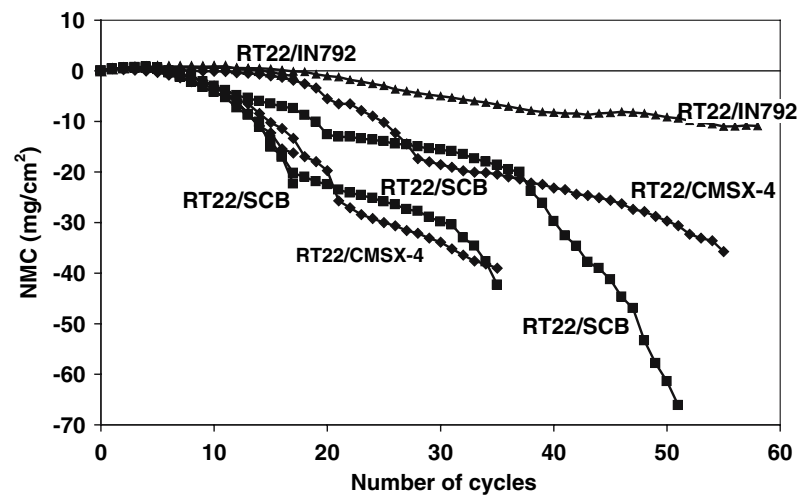

Fig. 2 Net mass change at $1,050{ }^{\circ} \mathrm{C}$ of each system after 17,35 and 51 , and 54 cycles of 300 h, i.e., $16,200 \mathrm{~h}$ in laboratory air

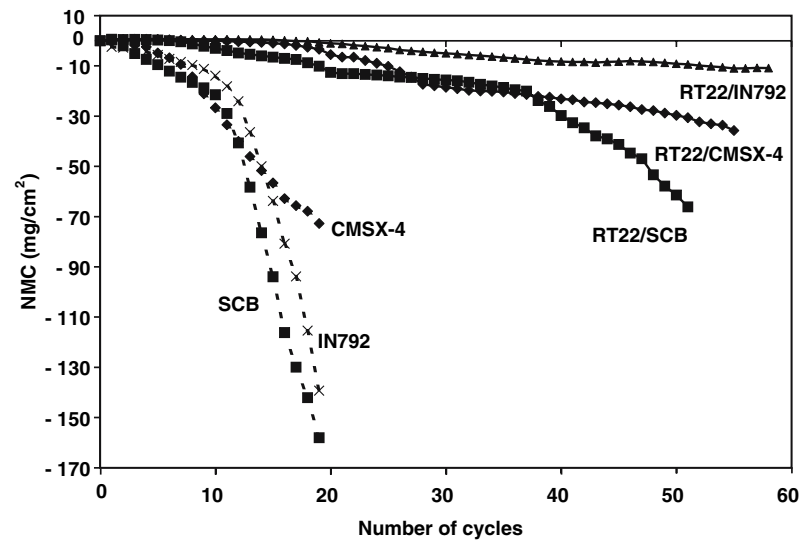

Fig. 3 Net mass change at $1,050{ }^{\circ} \mathrm{C}$ of each system after 54 and 51 cycles of $300 \mathrm{~h}$ and for superalloys CMSX-4, SCB, and IN792 after 19 cycles of $300 \mathrm{~h}$, i.e., 5,700 h in laboratory air

This observation can be explained by the higher Al content of CMSX-4 alloy (Table 1) which permits healing after spalling over a larger number of cycles for this alloy. The presence of reactive elements (RE) Hf and $\mathrm{Zr}$ in CMSX-4 and IN792 does not seem to reduce the alloying-element consumption rate during the first 10 cycles, in comparison with SCB alloy which has no RE and a lower Al content than CMSX-4.

In part I, a substrate effect was clearly observed during short-term, isothermaloxidation tests of $100 \mathrm{~h}$ at $900,1,050$, and $1,150{ }^{\circ} \mathrm{C}$ and long-term, cyclic-oxidation tests at $900{ }^{\circ} \mathrm{C}$, but it was of limited extent. Here, long-term cyclic-oxidation at $1,050{ }^{\circ} \mathrm{C}$ shows a larger effect of the substrate since NMC curves highlight that RT22 has better cyclic-oxidation behavior when deposited on IN792 than on CMSX-4 or SCB. 


\section{Microstructural Investigations}

The evolution of specimen surface morphology was followed by systematic SEM examination after a given number of oxidation cycles, usually 6,17 , and 35 cycles corresponding respectively to times at temperature of 1,800, 5,100, and 10,500 h. The area fractions of spalled scale were determined from back-scattered electron examinations (BSE). Indeed, the large difference in average atomic number of oxide scales and coatings leads to a strong contrast between spalled areas (brighter) and unspalled areas (darker). These highly contrasted BSE images allow for easy quantification of oxide scale spallation. Image analysis was performed with Aphelion software from ADCIS (Caen, France) to follow the variation of spalled fraction as a function of cycle number.

\section{Surface and Cross-section Morphologies of Oxide Scales}

Microstructural investigations were performed to confirm and understand the influence of the substrate on the observed cyclic-oxidation behavior. BSE images on Fig. 4 illustrate the significant effect of substrate on spalled area fraction and also on the morphology and size of spalled zones. The measured spalled area fractions are reported in Table 2. BSE images and spalled area fractions confirm the effect of the

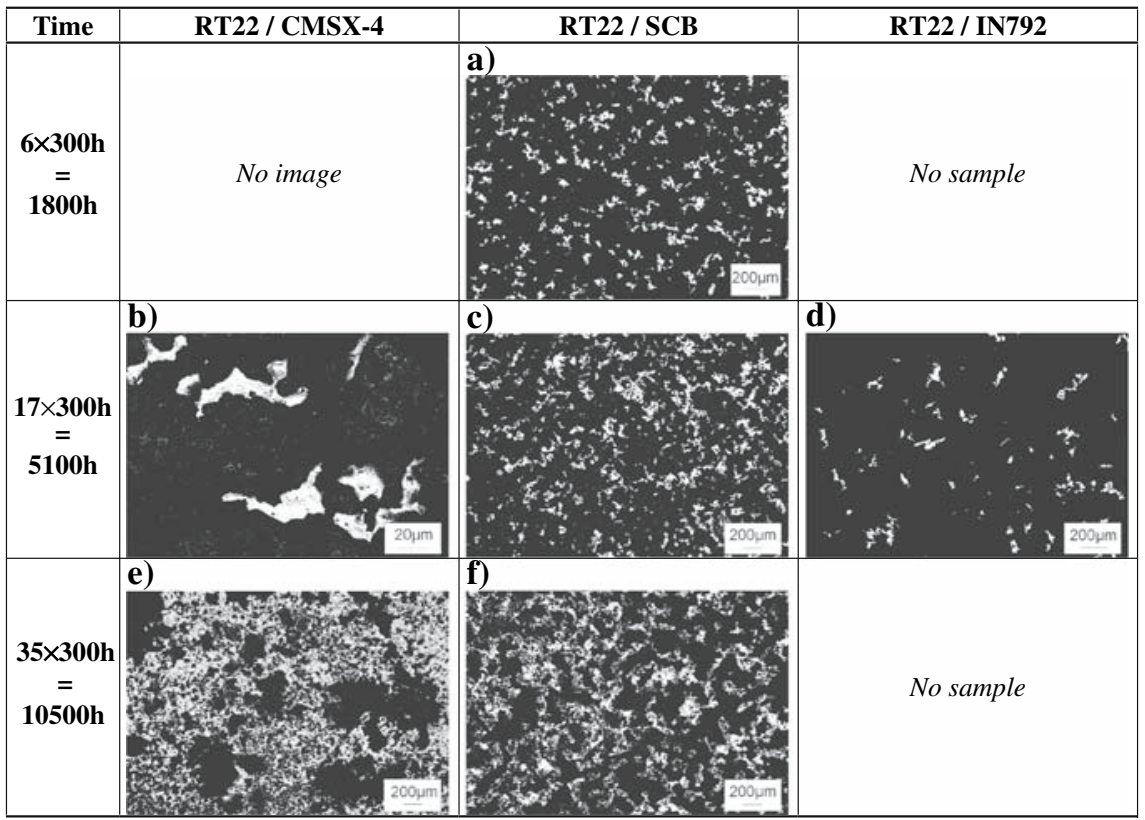

Fig. 4 SEM images (back-scattered electron) of sample surfaces after cyclic-oxidation at $1,050{ }^{\circ} \mathrm{C}$ $(6,17$, and 35 cycles) 
Table 2 Quantification of spalled area

\begin{tabular}{lccc}
\hline Sample & Number of objects & Average size (pixels) & Spalled fraction (\%) \\
\hline RT22/SCB $6 \times 300 \mathrm{~h}$ & 610 & 95 & 8.3 \\
RT22/SCB $17 \times 300 \mathrm{~h}$ & 1,376 & 51 & 10 \\
RT22/SCB $35 \times 300 \mathrm{~h}$ & 3,702 & 29 & 15 \\
RT22/IN792 $17 \times 300 \mathrm{~h}$ & 172 & 101 & 2.5 \\
RT22/CMSX-4 35 $\times 300 \mathrm{~h}$ & 2,125 & 92 & 28 \\
\hline
\end{tabular}

Results from image analysis ("objects" are the spalled areas)

substrate on the cyclic-oxidation behavior. Indeed, more intense scale spalling characterizes the RT22/CMSX-4 system compared to RT22/IN792, and the system RT22/SCB presents an intermediate behavior. These observations are consistent with the NMC curves (Figs. 1-3), and prove that the difference in cyclic-oxidation kinetics can be attributed, at least partially, to a different amount of oxide scale spalling. Moreover, it is observed that the area of freshly spalled scale significantly increases with the number of cycles.

The differences in surface morphology of the three coating systems studied after 17 cycles at $1,050{ }^{\circ} \mathrm{C}$ are illustrated by Figs. 5-7. EDS and XRD analysis showed that the oxide scale grown on RT22/CMSX-4 (Fig. 5) after 17 cycles is composed mainly of $\alpha-\mathrm{Al}_{2} \mathrm{O}_{3}$ and $\mathrm{NiAl}_{2} \mathrm{O}_{4}$ spinel with some amount of rutile phase $(\mathrm{Al}, \mathrm{Cr}, \mathrm{Ti})(\mathrm{Ta}, \mathrm{Ti}) \mathrm{O}_{4}$ as already detected and described in part I. In the SEM, spinel phases with a small grain size are observed above columnar grains of $\alpha-\mathrm{Al}_{2} \mathrm{O}_{3}$. $(\mathrm{Al}, \mathrm{Cr}, \mathrm{Ti})(\mathrm{Ti}, \mathrm{Ta}) \mathrm{O}_{4}$ rutile oxide is not distinguishable in this top-view SEM image. The same oxide phases with a similar microstructure were observed on RT22/SCB (Fig. 6) after the same number of cycles. Less $\mathrm{NiAl}_{2} \mathrm{O}_{4}$ spinel formed on RT22/ IN792 (Fig. 7). Analyzing the relative amount of the oxide phases as a function of the number of cycles by XRD (Figs. 8-10) clearly shows that the fraction of protective $\alpha-\mathrm{Al}_{2} \mathrm{O}_{3}$ decreases, whereas the fractions of spinel and rutile increase. $\mathrm{NiO}$ is also detected by SEM-EDS analysis after 35 cycles of $300 \mathrm{~h}$.

Fig. 5 Surface of RT22/ CMSX-4 after 17 cycles of $300 \mathrm{~h}(5,100 \mathrm{~h})$ at $1,050{ }^{\circ} \mathrm{C}$ in laboratory air (SEM)

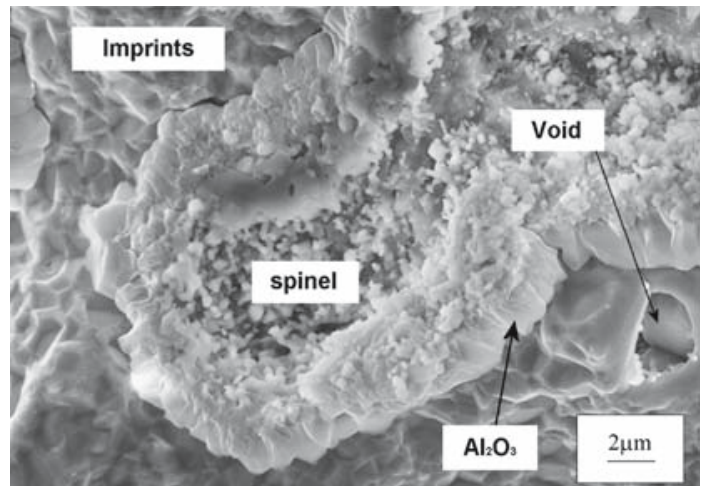


Fig. 6 Surface of RT22/SCB after 17 cycles of $300 \mathrm{~h}$ $(5,400 \mathrm{~h})$ at $1,050{ }^{\circ} \mathrm{C}$ in laboratory air (SEM)

Fig. 7 Surface of RT22/IN792 after 17 cycles of $300 \mathrm{~h}$ $(5,400 \mathrm{~h})$ at $1,050{ }^{\circ} \mathrm{C}$ in laboratory air (SEM)
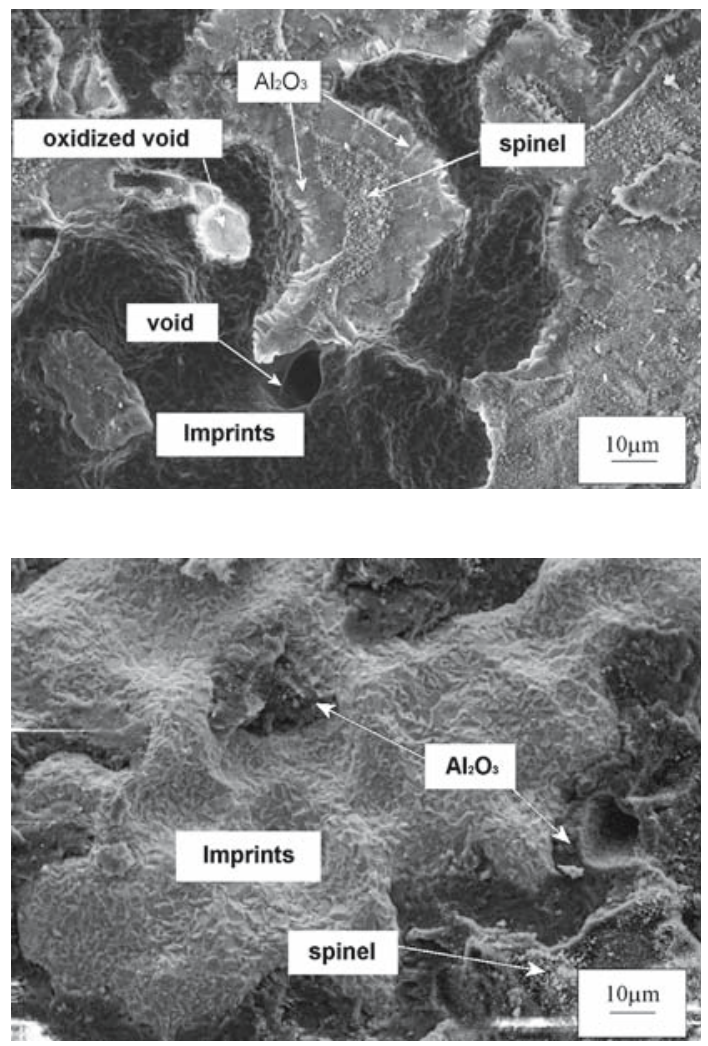

During SEM examination, the most noticeable feature is the presence of numerous voids on spalled areas for the RT22/CMSX-4 and RT22/SCB systems after 6, 17 (Figs. 5, 6), and 35 cycles of $300 \mathrm{~h}$ at $1,050{ }^{\circ} \mathrm{C}$. Such voids were not observed for the RT22/IN792 system (Fig. 7). Figure 6 shows an oxidized void surrounded by a spalled area. On the remaining of the spalled area, imprints of alumina grains are also observed. The image of the void observed on RT22/SCB after 17 cycles (Fig. 6) is enlarged in Fig. 11. These micrographs (Figs. 6, 11) show clearly that these interfacial voids are located at grain boundaries. The crosssections of the same samples (Figs. 12-14) confirm the absence of voids for RT22/ IN792 and the formation of large and deep voids for both of the other systems. Oxide scale formed on RT22/CMSX-4 after 17 cycles (Fig. 12) is not dense and continuous and consists on several layers of $\alpha-\mathrm{Al}_{2} \mathrm{O}_{3},(\mathrm{Al}, \mathrm{Cr}, \mathrm{Ti})(\mathrm{Ti}, \mathrm{Ta}) \mathrm{O}_{4}$ and $\mathrm{NiAl}_{2} \mathrm{O}_{4}$ spinel. Large pores were also observed in the oxide scale in addition with the large and deep pores opening at the coating/oxide interface (Fig. 12). Such large voids were previously observed on a similar system by Angenete et al. [2]. The oxide scale on RT22/SCB contains spinel phases and $\alpha-\mathrm{Al}_{2} \mathrm{O}_{3}$. As already shown with top view images (Figs. 6, 11), large and deep voids are also opening at the coating/oxide interface. The oxide scale on RT22/IN792, on the contrary, is 


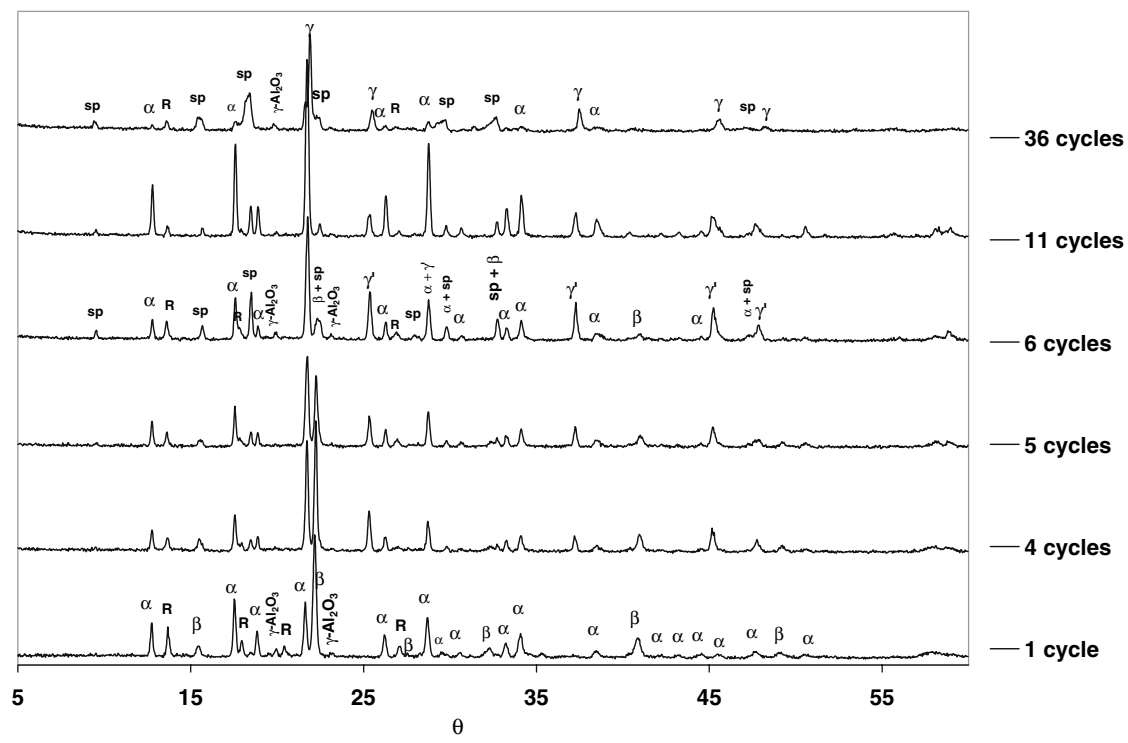

Fig. 8 XRD diagrams of RT22/CMSX-4 after cyclic-oxidation in laboratory air ( $300 \mathrm{~h}$ cycles). $\beta$ stands for $\beta$-NiAl, $\gamma^{\prime}$ for $\gamma^{\prime}-\mathrm{Ni}_{3} \mathrm{Al}, \alpha$ for $\alpha-\mathrm{Al}_{2} \mathrm{O}_{3}, \mathrm{R}$ for rutile oxide $\mathrm{TiO}_{2}$ or mixed, sp for spinel $\mathrm{NiAl}_{2} \mathrm{O}_{4}$ or others

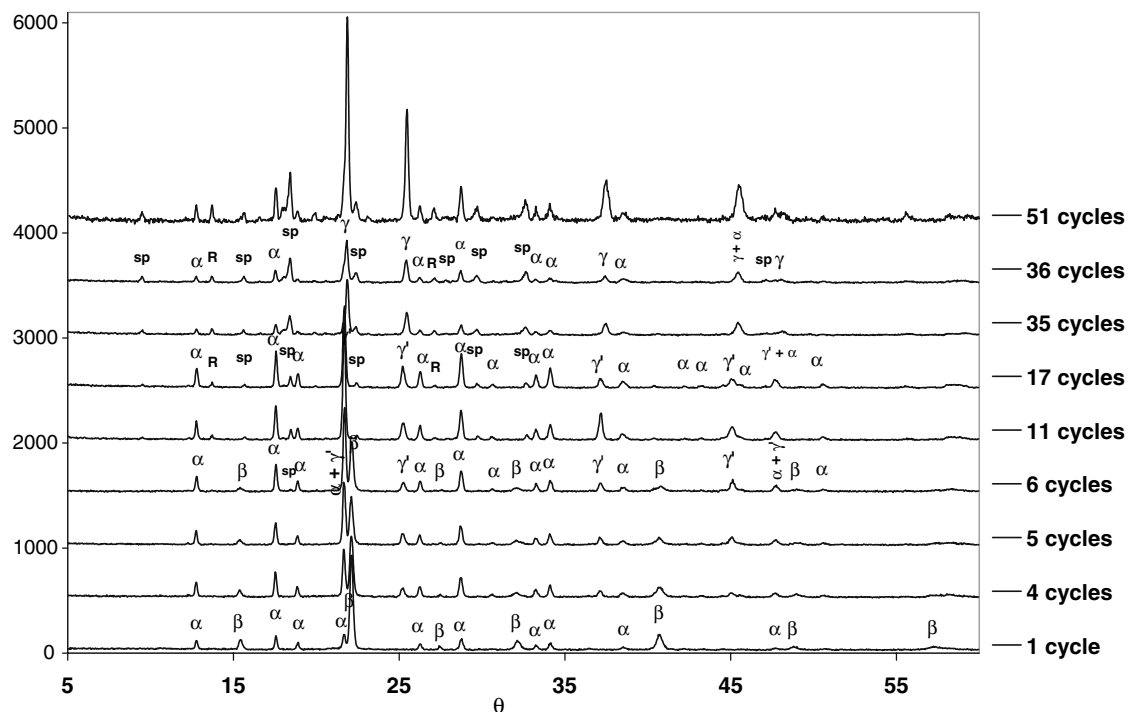

Fig. 9 XRD diagrams of RT22/SCB after cyclic-oxidation in laboratory air ( $300 \mathrm{~h}$ cycles). $\beta$ stands for $\beta$-NiAl, $\gamma^{\prime}$ for $\gamma^{\prime}-\mathrm{Ni}_{3} \mathrm{Al}, \alpha$ for $\alpha-\mathrm{Al}_{2} \mathrm{O}_{3}, \gamma$ for $\gamma-\mathrm{Al}_{2} \mathrm{O}_{3}, \mathrm{R}$ for rutile oxide $\mathrm{TiO}_{2}$ or mixed, sp for spinel $\mathrm{NiAl}_{2} \mathrm{O}_{4}$ or others 


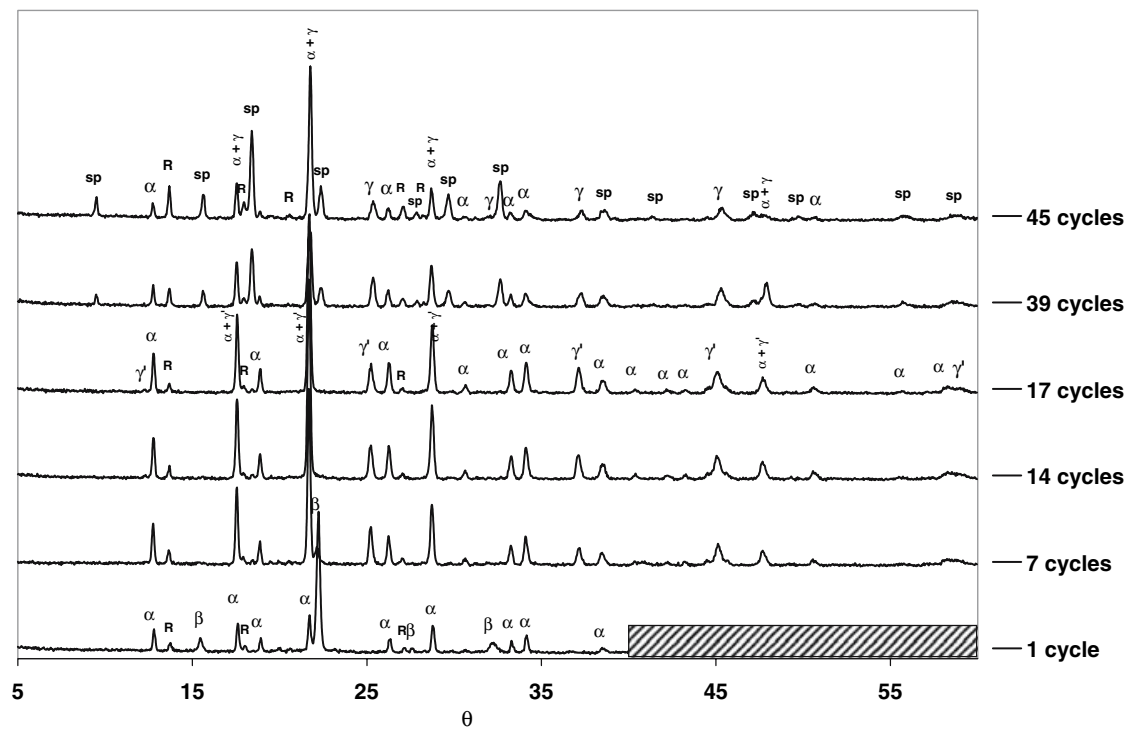

Fig. 10 XRD diagrams of RT22/IN792 after cyclic-oxidation in laboratory air (300 h cycles). $\beta$ stands for $\beta$-NiAl, $\gamma^{\prime}$ for $\gamma^{\prime}-\mathrm{Ni}_{3} \mathrm{Al}, \alpha$ for $\alpha-\mathrm{Al}_{2} \mathrm{O}_{3}, \gamma$ for $\gamma-\mathrm{Al} 2 \mathrm{O} 3$, $\mathrm{R}$ for rutile oxide $\mathrm{TiO}_{2}$ or mixed, sp for spinel $\mathrm{NiAl}_{2} \mathrm{O}_{4}$ or others

Fig. 11 Void formed on RT22/ SCB after 17 cycles of $300 \mathrm{~h}$ $(5,400 \mathrm{~h})$ at $1,050{ }^{\circ} \mathrm{C}$ in laboratory air

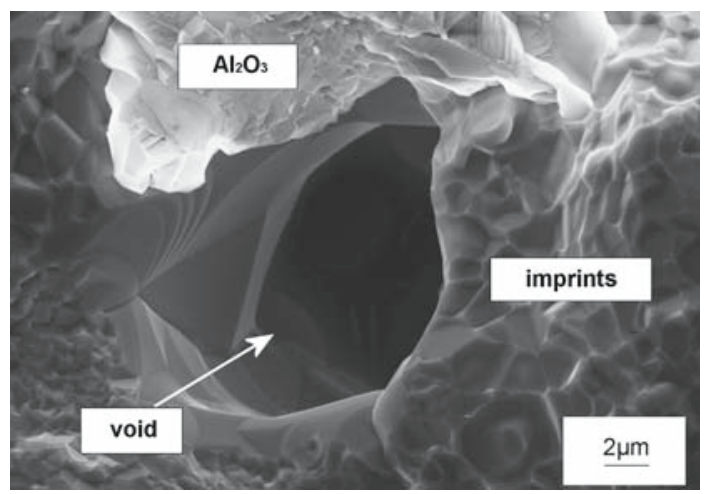

composed mainly of $\alpha-\mathrm{Al}_{2} \mathrm{O}_{3}$, which is adherent, dense, and continuous. This cross section confirms that no voids were observed at the coating/oxide interface.

These observations illustrate the strong influence of the substrate on the coatingsystem behavior. The systems which experience the formation and growth of large and deep voids are also experiencing the largest fraction of scale spallation (i.e., RT22/CMSX-4 and RT22/SCB). The best oxidation behavior is observed for the RT22/IN792 system which does not develop interfacial voids. Consequently, these voids likely act as nucleation sites for spalling. 
Fig. 12 Oxide scale formed on RT22/CMSX-4 after 17 cycles of $300 \mathrm{~h}(5,400 \mathrm{~h})$ at $1,050{ }^{\circ} \mathrm{C}$ in laboratory air

Fig. 13 Oxide scale formed on RT22/SCB after 17 cycles of $300 \mathrm{~h}(5,400 \mathrm{~h})$ at $1,050{ }^{\circ} \mathrm{C}$ in laboratory air

Fig. 14 Oxide scale formed on RT22/IN792 after 17 cycles of $300 \mathrm{~h}(5,400 \mathrm{~h})$ at $1,050{ }^{\circ} \mathrm{C}$ in laboratory air
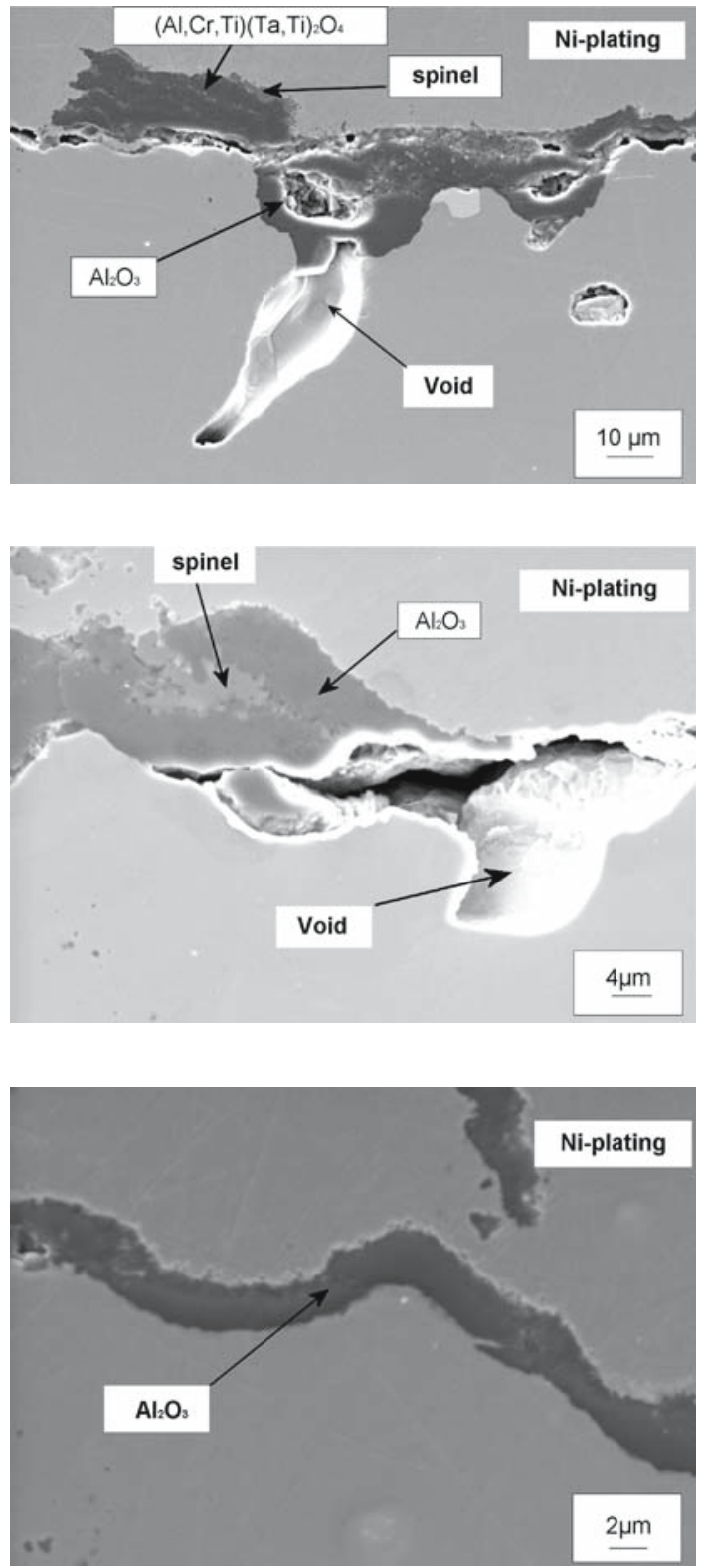

One alternative explanation of the better behavior of the RT22/IN792 system would be a possible effect of RE on oxide growth and spalling, as IN792 has more $\mathrm{Hf}$ and $\mathrm{Zr}$ than the other alloys. Indeed, the positive effect of Hf from the substrate on reducing the spalling of the oxide scale formed on $\mathrm{NiAl}$ coatings was documented by N'Gandu Muamba and Streiff [3]. Fisher et al. [4] have shown, on the contrary, the detrimental effect of excessive Hf content (ion implantation) in a 
platinum aluminide on a MarM002 substrate. A controlled addition of about 0.05 at\% Hf has been shown to improve oxide scale adherence on $\beta$-NiAl bulk material [5], while the quaternary additions of $\mathrm{Re}, \mathrm{Cr}$, Ti, and $\mathrm{Ta}$ were found to be detrimental to Hf-doped $\beta$-NiAl [6]. Thus, for long-term oxidation of a Pt-modified $\mathrm{NiAl}$ coating, with interdiffusion leading to a chemical and microstructural evolution of the surface alloy, it is difficult to draw definite conclusions concerning the effect of Hf. Without an efficient diffusion barrier between the coating and the substrate, it seems impossible to optimize the levels of reactive elements in the coating. It was observed in the present work that uncoated IN792 does not behave better than CMSX4 and SCB alloys (Fig. 3) despite a higher Hf content. Moreover, RT22/SCB has no RE and a lower Al content than CMSX-4 (Table 1) but has similar cyclic-oxidation kinetics over $35 \times 300$ h (Figs. 1, 2) than RT22/CMSX-4 which has Hf and $\mathrm{Zr}$. Finally, no Hf or $\mathrm{Zr}$ were detected in the oxide scale by SEMEDX and TEM-EDX [7]. For these reasons, the emphasis was placed on the observation of pores under the oxide scales formed on RTT22/CMSX-4 and RT22/ $\mathrm{SCB}$ and on the overall interdiffusion and phase transformation process.

\section{Microstructural Evolution of the Coatings}

Aluminum is the most efficient element to insure the protection of the systems studied against high-temperature oxidation. Consumption of aluminum is due to the coating oxidation leading to the growth of a protective alumina scale and to the diffusion of $\mathrm{Al}$ towards the superalloy substrate. Interdiffusion is also responsible for enrichment of the coating in alloying elements such as $\mathrm{Ni}, \mathrm{Co}, \mathrm{Cr}, \mathrm{Ti}, \mathrm{Ta}, \mathrm{Mo}, \mathrm{W}$ coming from the superalloy substrate. These changes in the chemical composition of the coating induce microstructural changes (major phases and precipitates). At $1050{ }^{\circ} \mathrm{C}$, interdiffusion is more significant than at $900{ }^{\circ} \mathrm{C}$ and microstructural changes are easy to observe. Only major phases evolution is described in the present work and the evolution of precipitated phases will be fully discussed in a forthcoming publication [8]. According to the $\mathrm{Ni}-\mathrm{Pt}-\mathrm{Al}$ phase diagram established by Gleeson et al. [9], the sequence of phase transformations within the coating is:

$$
\beta-\mathrm{NiAl} \rightarrow \gamma^{\prime}-\mathrm{Ni}_{3} \mathrm{Al} \rightarrow \gamma
$$

These phase transformations are controlled by the relative depletion in $\mathrm{Al}$ and $\mathrm{Pt}$ resulting from $\mathrm{Al}$ oxidation, $\mathrm{Al}$ and $\mathrm{Pt}$ diffusion towards the alloy, and by the arrival of $\mathrm{Ni}$ by interdiffusion from the substrate.

The microstructural evolution experienced by the coating/substrate systems was characterized for each studied system. Back-scattered electron SEM images of coating cross-sections after 6 and 17 cycles are shown in Fig. 15 for RT22/CMSX4, in Fig. 16 for RT22/SCB and in Fig. 17 for RT22/IN792. They can be compared with the microstructures of as-coated specimens which were detailed in part I of this work [1].

For RT22/CMSX-4, after 6 cycles of 300 h (Fig. 15a), some $\beta$-NiAl grains are partially transformed into $\gamma^{\prime}-\mathrm{Ni}_{3} \mathrm{Al}$ phase. The coating then forms two layers (one 

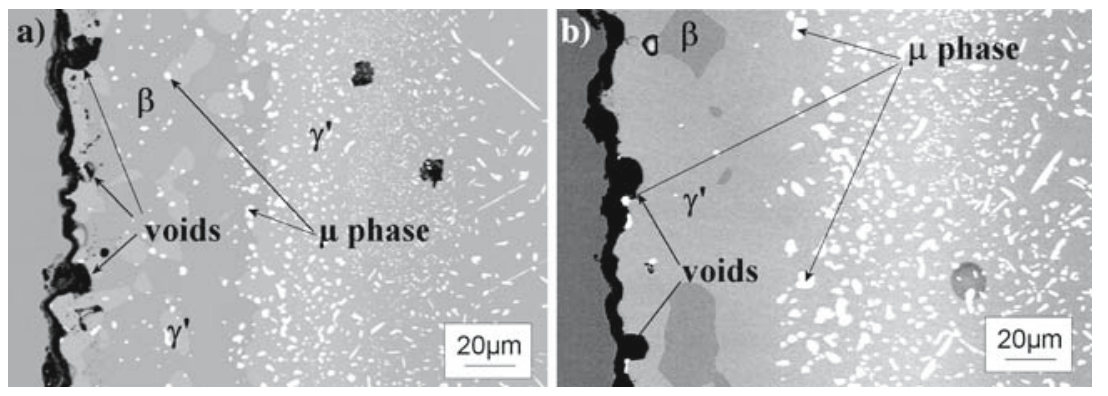

Fig. 15 Microstructural evolution of RT22/CMSX-4 after (a) 6 and (b) 17 cycles of $300 \mathrm{~h}$ at $1,050{ }^{\circ} \mathrm{C}$ in laboratory air
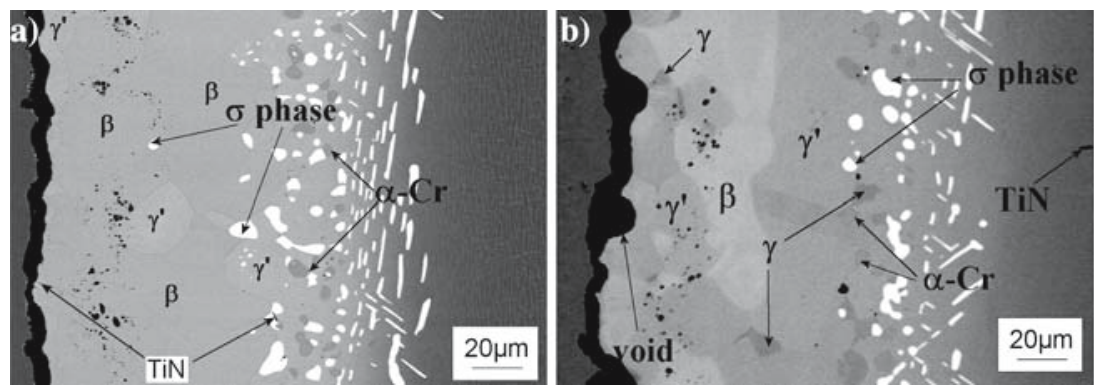

Fig. 16 Microstructural evolution of RT22/SCB after (a) 6 and (b) 17 cycles of $300 \mathrm{~h}$ at $1,050{ }^{\circ} \mathrm{C}$

external and one middle) parallel to the interface. Both layers are a mixture of $\beta$-NiAl and $\gamma^{\prime}-\mathrm{Ni}_{3} \mathrm{Al}$ grains. $\mathrm{A} \gamma^{\prime}-\mathrm{Ni}_{3} \mathrm{Al}$ single-phase zone, $30 \mu \mathrm{m}$ thick, is observed within the interdiffusion zone. After 17 cycles (Fig. 15b), a few $\beta$-NiAl grains were still observed in the middle zone. In both cases (Figs. 15a, b), several voids were observed close to the coating/oxide interface. Voids are sometimes linked to the surface, as is the void shown in Fig. 12, and some of them are oxidized.

For RT22/SCB, after 6 cycles of $300 \mathrm{~h}$ (Fig. 16a), some $\gamma^{\prime}-\mathrm{Ni}_{3} \mathrm{Al}$ grains were observed at the coating/oxide interface, in the middle zone and within the interdiffusion zone. As for RT22/CMSX-4, they form an external layer with $\beta$-NiAl and $\gamma^{\prime}-\mathrm{Ni}_{3} \mathrm{Al}$ grains at the coating/oxide interface and a $\gamma^{\prime}-\mathrm{Ni}_{3} \mathrm{Al}$ single-phase zone, $20-\mu \mathrm{m}$ thick, within the interdiffusion zone. Titanium nitrides were also observed in this system close to the surface and in the interdiffusion zone. $\mathrm{Ni}-\mathrm{Al}-\mathrm{Cr}-\mathrm{Ti}$ alloys oxidized in air form nitrides when the oxide scale is not an efficient barrier for nitrogen and this is the case when spalling occurs during cyclic-oxidation [10]. Nitrides are observed deeper than internal oxides because these nitrides are less stable than the corresponding oxides. After 17 cycles (Fig. 16b), the $\gamma$ phase in addition to $\beta$ - NiAl and $\gamma^{\prime}-\mathrm{Ni}_{3} \mathrm{Al}$ was identified in the coating close to the coating/ oxide interface, in the middle zone and in the interdiffusion zone. The $\gamma$ phase formed by $\mathrm{Al}$ depletion of $\gamma^{\prime}-\mathrm{Ni}_{3} \mathrm{Al}$ phase and/or by diffusion of $\mathrm{Ni}$ from the substrate to the coating or diffusion of alloying elements such as $\mathrm{Cr}$ and $\mathrm{Co}$ which 

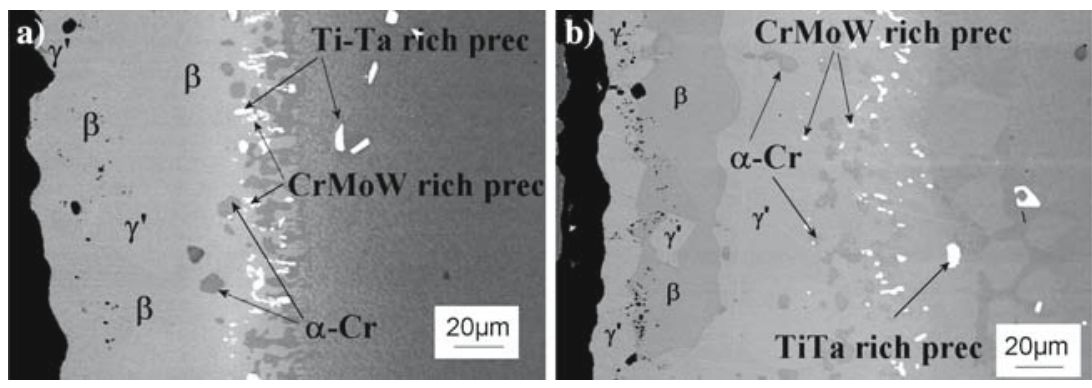

Fig. 17 Microstructural evolution of RT22/IN792 after (a) 6 and (b) 17 cycles of $300 \mathrm{~h}$ at $1,050{ }^{\circ} \mathrm{C}$ in laboratory air

stabilize the $\gamma$ phase [11]. As for RT22/CMSX-4, deep voids connected to the coating/oxide interface were also observed in this system.

For RT22/IN792, after 6 cycles of $300 \mathrm{~h}, \gamma^{\prime}-\mathrm{Ni}_{3} \mathrm{Al}$ grains form a $20-\mu \mathrm{m}$ thick, single-phase layer close to the surface and parallel to the coating/oxide interface (Fig. 17a). Another $\gamma^{\prime}-\mathrm{Ni}_{3} \mathrm{Al}$ single-phase zone, 20- $\mu \mathrm{m}$ thick, was observed close to the interdiffusion zone. Between these two single-phase zones, the middle zone is composed of large $\beta$-NiAl grains and a few $\gamma^{\prime}-\mathrm{Ni}_{3} \mathrm{Al}$ grains. After 17 cycles (Fig. 17b), the microstructure of the coating is similar to that after 6 cycles. This observation suggests that the $\beta / \gamma^{\prime}$ transformation progresses parallel to the coating/ oxide interface. In this system, relatively few pores were observed, contrary to the RT22/CMSX-4 and RT22/SCB coating systems. These few pores are not located close to the surface and are not connected to it. They were observed at about $20 \mu \mathrm{m}$ from the surface, at the boundary between the $\gamma^{\prime}-\mathrm{Ni}_{3} \mathrm{Al}$ single-phase layer and the $\beta$-NiAl middle zone.

The main difference between the three systems studied lies in the morphology of the phase distribution resulting from the $\beta$-NiAl $\rightarrow \gamma^{\prime}-\mathrm{Ni}_{3} \mathrm{Al}$ phase transformation. In the RT22/CMSX-4 and RT22/SCB systems, a $\beta+\gamma^{\prime}$ two-phase layer formed close to the coating/oxide interface, whereas in RT22/IN792 the transformation leads to an external $\gamma^{\prime}$ single-phase zone parallel to the coating/oxide interface, indicating that the $\beta$ to $\gamma^{\prime}$ transformation front moves gradually inward. For the first specific microstructure (i.e., of RT22/CMSX-4 and RT22/SCB) interfacial voids were observed but not in the second case (i.e., RT22/IN792) where only a few voids were detected and located far from the coating/oxide interface.

\section{Discussion}

During short-term $(100 \mathrm{~h})$, isothermal-oxidation tests in the temperature range of 900-1,150 ${ }^{\circ} \mathrm{C}$ and long-term, cyclic-oxidation tests at $900{ }^{\circ} \mathrm{C}$, the substrate effect was limited and could be attributed to differences in the initial chemical composition of the coating surface induced by differences in alloy compositions and thermal treatments of the coating systems (cf. part I [1]). At 1,050 ${ }^{\circ} \mathrm{C}$, the effect 
of the substrate on the long-term, cyclic-oxidation behavior becomes more important. This effect cannot be linked to the surface roughness because, as reported in part $\mathrm{I}$, roughness parameters $\mathrm{R}_{\mathrm{a}}$ were similar for the systems studied. Observation of surface and cross sections of coating systems showed that spalling is favored by the presence of deep and large voids formed at the coating/oxide interface. These observations suggest that some of them could act as nucleation sites for scale spallation. The formation of such interfacial voids was always observed when the $\beta$ to $\gamma^{\prime}$ transformation leads to an external two-phase $\beta+\gamma^{\prime}$ layer. No voids were observed on the contrary when this $\beta$ to $\gamma^{\prime}$ transformation occurred gradually by an inward transformation of $\beta$ leading to the formation of a continuous layer of $\gamma^{\prime}$ phase, parallel to the interface.

\section{Void Formation at the Metal/Oxide Interface}

Many studies have shown that voids are formed at the metal/oxide interface during oxidation of $\beta$-NiAl and $\gamma^{\prime}-\mathrm{Ni}_{3} \mathrm{Al}$ [12-19]. Some authors proposed that these voids grow by vacancy coalescence. Two hypotheses based on diffusion phenomena are suggested. First, Al consumption to form alumina scale creates an Al-depleted zone in the $\mathrm{NiAl}$ alloy beneath the oxide scale, leading to an $\mathrm{Al}$ concentration gradient which creates an outward $\mathrm{Al}$ flow and an inward Ni flow. As Ni diffuses faster than $\mathrm{Al}$ in $\mathrm{Ni}$-rich $\mathrm{NiAl}$, the difference between $\mathrm{Ni}$ and $\mathrm{Al}$ diffusion fluxes must be compensated by local vacancy sources equivalent to an outward vacancy flow toward the metal/oxide interface. If these vacancies are not annihilated at the interface, they can coalesce and form interfacial voids [13, 20]. A second source of vacancies and voids can be associated with scale growth mechanisms. Indeed, if the growth of transient alumina is cationic for each atom of $\mathrm{Al}$ consumed, an $\mathrm{Al}$ vacancy is created at the metal-scale interface if the interface is not able to move in order to annihilate the resulting vacancy. These vacancies can also coalesce to form interfacial voids [21]. In the present study, the mechanism of void formation may be different. Indeed, the voids observed are deep and located at grain boundaries where $\beta$-NiAl is locally transformed to $\gamma^{\prime}-\mathrm{Ni}_{3} \mathrm{Al}$, and some of them are connected to the surface. Such voids, named "wormholes" were previously observed by Haynes et al. [22], Angenete et al. [2] and Kim et al. [23]. Kim et al. associated the voids formation with the high frequency of thermal cycling and to a creep cavitation mechanism. This is certainly not the case in the present study because of the very low frequency of thermal cycling. Tolpygo and Clarke [24] noticed that the transformation of $\beta$-NiAl to $\gamma^{\prime}-\mathrm{Ni}_{3} \mathrm{Al}$ leads to a considerable volume reduction and they attributed to this local volume change the observed surface distortions ("rumpling") or the formation of interfacial cavities. These authors describe the decomposition of $\beta$-phase during oxidation by the following reaction:

$$
3 \mathrm{NiAl}+3 / 2 \mathrm{O}_{2} \rightarrow \mathrm{Ni}_{3} \mathrm{Al}+\mathrm{Al}_{2} \mathrm{O}_{3}
$$

After calculation of molar volumes of each phase, they propose that the volume change associated with this reaction is: 


$$
\mathrm{V}\left(\gamma^{\prime}\right)=0.62 \mathrm{~V}(\beta)
$$

As highlighted by Zhang et al. [25], this reaction does not take into account stoichiometry. Indeed, when $\beta$-NiAl transforms to $\gamma^{\prime}-\mathrm{Ni}_{3} \mathrm{Al}$, phase compositions are not stoichiometric. According to the $\mathrm{Ni}-\mathrm{Al}$ phase diagram [26], the phases compositions are rather $\mathrm{Ni}_{1.3} \mathrm{Al}_{0.7}$ and $\mathrm{Ni}_{2.9} \mathrm{Al}_{1.1}$ and the reaction becomes:

$$
0.77 \mathrm{Ni}_{1.3} \mathrm{Al}_{0.7}+0.12 \mathrm{O}_{2} \rightarrow 0.34 \mathrm{Ni}_{2.9} \mathrm{Al}_{1.1}+0.08 \mathrm{Al}_{2} \mathrm{O}_{3}
$$

Using molar volumes calculated with lattice parameters measured from our XRD analysis, the volume change associated with this last reaction is:

$$
\mathrm{V}\left(\gamma^{\prime}\right)=0.84 \mathrm{~V}(\beta)
$$

For RT22/CMSX-4 and RT22/SCB, the $\beta$ to $\gamma^{\prime}$ transformation occurs locally at the coating/oxide interface, leading to a two-phase $\beta+\gamma^{\prime}$ layer parallel to the interface (Fig. 18). Therefore, assuming local equilibrium at the coating/oxide interface between $\beta$-NiAl, $\gamma^{\prime}-\mathrm{Ni}_{3} \mathrm{Al}$ and $\mathrm{Al}_{2} \mathrm{O}_{3}$ the reaction $\mathrm{R} .2$ applies and the volume reduction due to the transformation is $16 \%$ (Eq. (2)). The average size of one $\beta$-NiAl grain in RT22/CMSX-4 is reported in Fig. 19. This grain size corresponds to an average grain volume of about $4,000 \mu \mathrm{m}^{3}$. Thus, as shown in Fig. 19, the transformation of three adjacent $\beta$-NiAl grains into three $\gamma^{\prime}-\mathrm{Ni}_{3} \mathrm{Al}$ grains leads to a volume change of $\Delta \mathrm{V}=-1900 \mu \mathrm{m}^{3}$. Such a value is compatible with the volume of voids observed in RT22/CMSX-4 after 17 cycles of $300 \mathrm{~h}$ at $1,050{ }^{\circ} \mathrm{C}$ (Fig. 12) and which was estimated to be about $1,500 \mu^{3}$. Then, it is proposed that the formation of the grain boundary and interfacial voids observed in the present study is due to the volume reduction associated with the local $\beta \rightarrow \gamma^{\prime}$ transformation.

However, the contribution of diffusion mechanisms described earlier cannot be neglected. Namely, interfacial voids can nucleate by vacancy coalescence and grow at grain boundaries because of the volume reduction linked to the $\beta$ to $\gamma^{\prime}$
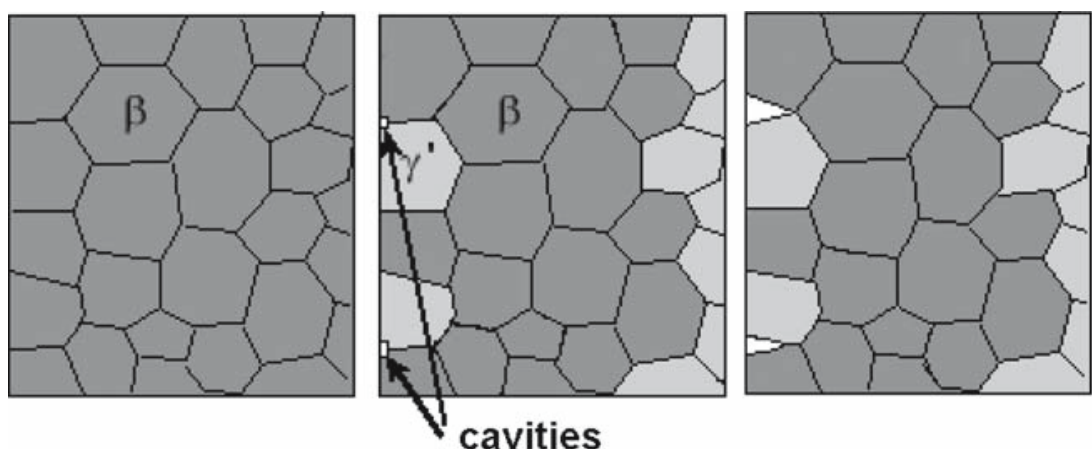

Fig. 18 Void-formation mechanism at metal/oxide interface on RT22/CMSX-4 and RT22/SCB, when $\gamma^{\prime}$ is dispersed at the interface 

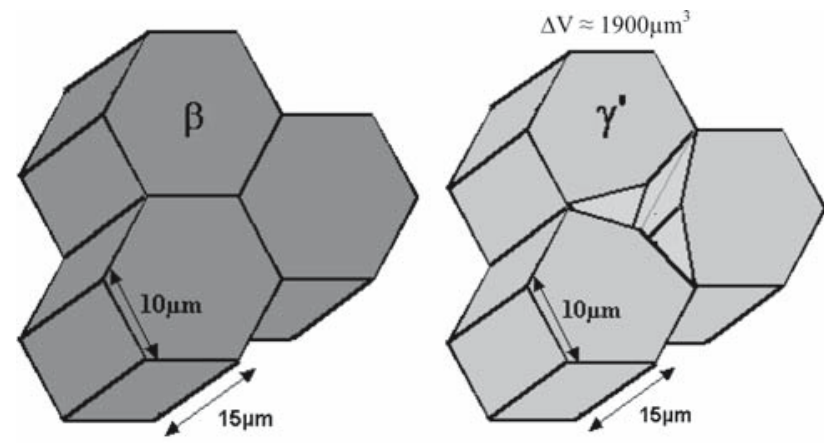

Fig. 19 Volume change due to $\beta$ to $\gamma^{\prime}$ transformation

transformation. Conversely, void nucleation can be induced by volume reduction, and voids can grow by acting as a sink for the incoming vacancies (Fig. 18).

In RT22/IN792 the transformation of $\beta$-NiAl to $\gamma^{\prime}-\mathrm{Ni}_{3} \mathrm{Al}$ takes place uniformly over the whole surface under the oxide scale, and $\gamma^{\prime}-\mathrm{Ni}_{3} \mathrm{Al}$ grains form a uniform single-phase layer under the oxide scale, parallel to the interface (Fig. 17). In that case, equilibrium between $\mathrm{Al}_{2} \mathrm{O}_{3}, \beta$-NiAl and $\gamma^{\prime}-\mathrm{Ni}_{3} \mathrm{Al}$ does not exist. The $\beta$-NiAl phase transforms to $\gamma^{\prime}-\mathrm{Ni}_{3} \mathrm{Al}$, by $\mathrm{Al}$ consumption to form an alumina scale or by $\mathrm{Ni}$ diffusion from the substrate, according to two reactions:

$$
\begin{gathered}
0.77 \mathrm{Ni}_{1.3} \mathrm{Al}_{0.7} \rightarrow 0.34 \mathrm{Ni}_{2.9} \mathrm{Al}_{1.1}+0.159 \mathrm{Al} \\
1.43 \mathrm{Ni}_{1.3} \mathrm{Al}_{0.7}+0.78 \mathrm{Ni} \rightarrow 0.91 \mathrm{Ni}_{2.9} \mathrm{Al}_{1.1}
\end{gathered}
$$

Reactions R.2 and R.3 lead to a similar volume change (Eq. (2)), but the volume change resulting from R.4 is a volume increase:

$$
\mathrm{V}\left(\gamma^{\prime}\right)=1.2 \mathrm{~V}(\beta)
$$

Then, in RT22/IN792, the volume change associated to the $\beta \rightarrow \gamma^{\prime}$ transformation can vary from a reduction of $16 \%$ up to an expansion of $20 \%$. The actual volume changes will depend on the predominant reaction (Al consumption or $\mathrm{Ni}$ gain at the $\beta / \gamma^{\prime}$ interface). However, in both cases, the specific microstructure of RT22/IN792 allows the shift of the surface gradually inward as the $\beta / \gamma^{\prime}$ transformation front progresses, so the volume change associated with the $\beta / \gamma^{\prime}$ transformation is compensated by the interface motion and voids are not formed (Fig. 20).

\section{Oxide Scale Spallation}

The specific microstructure observed for RT22/CMSX-4 and RT22/SCB systems (i.e., $\beta+\gamma^{\prime}$ two-phase layer parallel to the interface) leads to formation of deep voids which can act as nucleation sites for spallation. The rutile oxide phase 

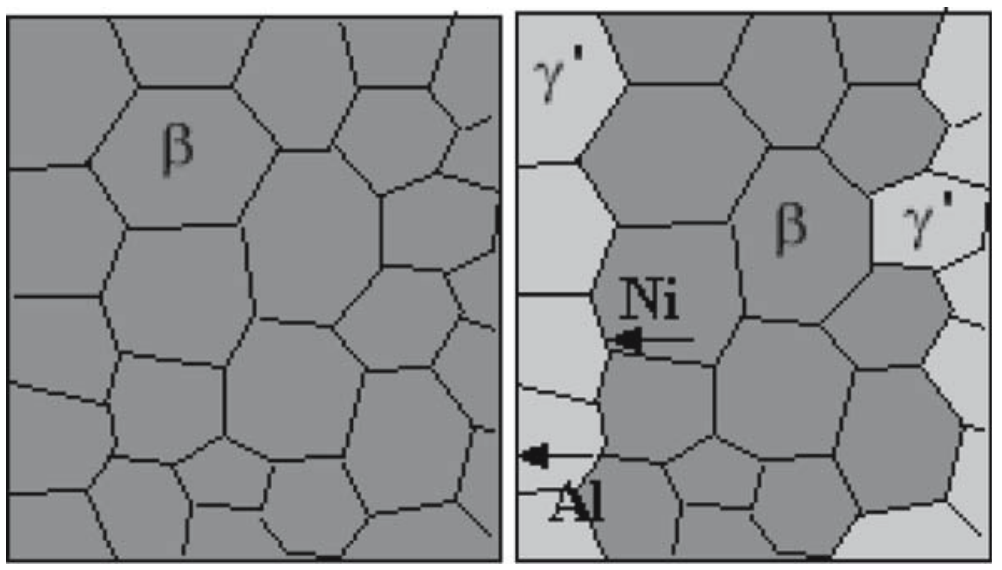

Fig. $20 \beta$ to $\gamma^{\prime}$ transformation parallel at the metal/oxide interface creates a single-phase zone. Volume change due to the transformation is compensated by the moving interface

detected from the first hours of oxidation on RT22/CMSX-4 and RT22/IN792 appeared to be detrimental to oxide scale adherence during short-term isothermal oxidation and long-term cyclic oxidation at $900{ }^{\circ} \mathrm{C}$ (cf. Part I [1]). Nevertheless, during long-term, cyclic-oxidation tests at $1,050{ }^{\circ} \mathrm{C}$, this detrimental effect is small compared to the detrimental effect of voids. Indeed, for the same relative amount of $\mathrm{TiO}_{2}$ on RT22/CMSX4 and RT22/IN792, the total spalled area is lower for RT22/ IN792. Image analysis showed for RT22/SCB that freshly spalled area increases with the number of cycles during the first 35 cycles. Evans emphases that spalled area for each cooling depends on oxide-scale thickness [27]. The present crosssection examinations showed that oxide scale thickness increases from $3.4 \mu \mathrm{m}$ to $10 \mu \mathrm{m}$ between the 6th and 17 th cycles. However, after 35 cycles, the oxide scale was not thicker than after 17 cycles. This observation shows that in the present case, oxide scale spallation is not only controlled by oxide scale thickness but also by the nature of the oxide formed (more spinel phases after 35 cycles than after 17 cycles) or by the number of deep interfacial voids. Indeed, the number of these voids increases with the amount of $\beta$ phase transformed to $\gamma^{\prime}$ phase and then with the number of cycles.

\section{Substrate Effect}

Short-term, isothermal-oxidation tests between 900 and $1,150{ }^{\circ} \mathrm{C}$ and long-term, cyclic-oxidation tests at $900{ }^{\circ} \mathrm{C}$ were not damaging enough to highlight which system was the most resistant. The present work shows clearly the better cyclicoxidation behavior of RT22/IN792 during long-term, cyclic-oxidation tests at $1,050{ }^{\circ} \mathrm{C}$. The nature of the substrate has an effect on cyclic-oxidation kinetics (Figs. 1-3), on spalled area fraction (Fig. 4, Table 2) and on microstructural evolution (Figs. 15-17). In the coating system RT22/IN792, $\beta$-NiAl transforms to 
$\gamma^{\prime}-\mathrm{Ni}_{3} \mathrm{Al}$ by forming a single-phase layer that gradually moves inward, parallel to the interface. This specific microstructure avoids the formation of interfacial voids and thus limits scale spallation. This is not the case in the two other systems in which the $\beta$ to $\gamma^{\prime}$ phase transformation occurs at $\beta$-NiAl grain boundaries. The reason why the topology of the phase transformation is different in the case of the RT22/IN792 system than in the case of RT22/SCB and RT22/CMSX4 is unknown. The initial microstructure of the RT22 coating is similar for the 3 systems, and the initial roughness is also the same. The explanation for difference in phase transformation topology is certainly linked to the chemical composition of the coating which depends on the substrate after long oxidation times, and affects the phase transformation. Additional analysis is required to precisely explain this observation. As shown in another publication [8] substrate has also an effect on interdiffusion which it is less pronounced for the RT22/IN792 system. Protection insured by $\mathrm{Al}$ is then preserved during a longer time and $\beta$ to $\gamma^{\prime}$ transformation is delayed. The better cyclic-oxidation behavior of RT22/IN792 is due to the chemical composition of the coating system that depends on the superalloy substrate. Because of the complexity of the systems studied, particularly their complex chemical composition characterized by the large number of chemical elements present in the coating and its superalloy substrate, many aspects remain to be investigated. Especially, an assessment of how chemical elements interact with each other and the function of each one on diffusion processes and phase transformations needs to be performed. In RT22/CMSX-4, $\mu$-phase precipitates containing $\mathrm{Re}, \mathrm{W}, \mathrm{Cr}$, and Co form preferentially in grain boundaries. These precipitates could slow down the diffusion process and the $\beta$ to $\gamma^{\prime}$ transformation. Indeed, a large amount of $\mathrm{W}$ in these precipitates prevents the destabilizing effect of this element on $\beta$ - $\mathrm{NiAl}$ and then delays the formation of $\gamma^{\prime}-\mathrm{Ni}_{3} \mathrm{Al}$.

CMSX-4 has the best cyclic-oxidation resistance of the three alloys studied (Fig. 3). Despite this, the system RT22/IN792 is superior to the system RT22/ CMSX-4. This fact demonstrates the importance of the interactions between the superalloy and its coating, namely the importance of the interdiffusion.

\section{Conclusions}

The study of the long-term cyclic-oxidation at $1,050{ }^{\circ} \mathrm{C}$, up to 58 cycles of $300 \mathrm{~h}$ (i.e., 17,400 h), of the same Pt-modified-aluminide coating RT22 deposited on three different Ni-base superalloys (CMSX-4, SCB, and IN792) leads to several conclusions:

1. NMC curves show that uncoated CMSX-4 has the best long-term, cyclicoxidation resistance of the three superalloys studied. However, the coating system RT22/IN792 has the best long-term, cyclic-oxidation behavior of the three coating systems studied. This fact demonstrates the importance of the interdiffusion between the superalloy and its coating.

2. Surface and cross-section analysis of the coating systems showed that spalling is favored by the presence of deep and large "wormhole" voids formed at the 
coating/oxide interface. Some of them could act as nucleation sites for scale spallation. The formation of such interfacial voids was always observed in RT22/CMSX-4 and RT22/SCB when the $\beta$ to $\gamma^{\prime}$ transformation leads to an external two-phase $\beta+\gamma^{\prime}$ layer. On the contrary, no voids were observed on RT22/IN792 when the $\beta$ to $\gamma^{\prime}$ transformation occurs gradually by an inward transformation of $\beta$ leading to the formation of a continuous layer of $\gamma^{\prime}$ phase, parallel to the interface.

3. In RT22/CMSX-4 and RT22/SCB, the formation of deep and large interfacial voids could be linked to the volume reduction due to the local $\beta \rightarrow \gamma^{\prime}$ transformation. The mechanism proposed in the present paper suggests that interfacial voids can nucleate by vacancy coalescence and grow at grain boundaries because of volume reduction linked to the $\beta$ to $\gamma^{\prime}$ transformation. Conversely, void nucleation can be induced by volume reduction and voids can grow by acting as sinks for the vacancies. The specific microstructure of RT22/ IN792 allows the motion of the surface gradually inward as the $\beta / \gamma^{\prime}$ transformation front progresses, so the volume change associated to the $\beta / \gamma^{\prime}$ transformation is compensated by the interface movement and voids are not formed.

4. In part I, a rutile oxide phase was detected from the first hours of oxidation on RT22/CMSX-4 and RT22/IN792. This rutile oxide appeared to be detrimental to oxide-scale adherence during short-term isothermal oxidation and long-term cyclic-oxidation at $900{ }^{\circ} \mathrm{C}$. Nevertheless, XRD diagrams and measured area fractions of spalled scale show that during long-term, cyclic-oxidation tests at $1,050{ }^{\circ} \mathrm{C}$, this detrimental effect is small compared to the detrimental effect of deep interfacial voids.

5. SEM images of coating cross-sections and measurement of the area fractions of spalled scale show that oxide scale spallation is not only controlled by oxidescale thickness, but also by the nature of the oxide formed and/or by the density of deep interfacial voids.

6. The better cyclic-oxidation behavior of RT22/IN792 is due to the nature of the superalloy substrate which modifies the chemical composition of the coating and then influences the phase-transformation topology in the system with consequences for pore formation and $\mathrm{Al}$ diffusion.

7. Although the RT22/IN792 system has better long-term, cyclic-oxidation behavior, its use in service is limited to specific gas-turbine components because of its lower mechanical properties at high temperature. If used at lower temperature, pure oxidation is not as damaging as hot corrosion, and other coatings such as MCrAlYs may be preferred. Nevertheless, the superiority of the system RT22/IN792 shows that the usual system RT22/CMSX-4, often quoted as a reference for its cyclic-oxidation behavior, could still be improved through slight modifications of its chemical composition or by integrating a diffusion barrier between the coating and the superalloy substrate in order to limit phase transformations in the coating. 
Acknowledgments The authors thank EEC for financial support through the European project Allbatros (NENK5-CT2000-00081) and all partners for their contribution. Sincere thanks are expressed to Prof. B. Pieraggi for fruitful discussions and helpful comments on the manuscript, and to Prof. G.H. Meier for reviewing the manuscript before its submission.

\section{References}

1. N. Vialas and D. Monceau, Oxidation of Metals 66, 155 (2006).

2. J. Angenete, K. Stiller, and V. Langer, Oxidation of Metals 60, 83 (2003).

3. J. M. N'Gandu Muamba and R. Streiff, MSE 88, 111 (1987).

4. G. Fisher, P. K. Datta, and J. S. Burnell-Gray, Surface \& Coatings Technology 110, 24 (1998).

5. B. A. Pint, I. Wright, and W. Lee, MSE A245, 201 (1998).

6. B. A. Pint, K. L. More, and I. G. Wright, Oxidation of Metals 59(3), 257 (2003).

7. N. Vialas, Ph.D thesis, Institut National Polytechnique de Toulouse (2004).

8. N. Vialas and D. Monceau, to be published.

9. B. Gleeson, W. Wang, S. Hayashi, and D. Sordelet, Materials Science Forum 461-464, 213 (2004).

10. U. Krupp and H.-J. Christ, Oxidation of Metals 52(3-4), 299 (1999).

11. C. C. Jia, K. Ishida, and T. Nishizawa, Metallurgical and Materials Transactions 25A, 173 (1994).

12. F. A. Golightly, F. H. Stott, and G. C. Wood, Oxidation of Metals 10, 163 (1976).

13. H. M. Hindam and W. W. Smeltzer, Journal of the Electrochemical Society 127, 1630 (1980).

14. M. W. Brumm and H. J. Grabke, Corrosion Science 34, 547 (1993).

15. J. L. Smialek, Metallurgical and Materials Transactions 9A, 309 (1978).

16. M. Bobeth, E. Bischoff, E. Schumann, M. Rockstroh, and M. Rühle, Corrosion Science 37, 657 (1995).

17. H. Hindam and D. P. Whittle, Oxidation of Metals 18, 245 (1982).

18. J. C. Yang, K. Nadarzinski, E. Schumann, and M. Ruhle, Scripta Metallurgica et Materialia 33, 1043 (1995).

19. D. Oquab and D. Monceau, Materials Science Forum 369-372, 499 (2001).

20. J. D. Kuenzly and D. L. Douglass, Oxidation of Metals 8, 139 (1974).

21. L. Rivoaland, V. Maurice, P. Josso, M.-P. Bacos, and P. Marcus, Oxidation of Metals 60, 159 (2003).

22. J. A. Haynes, B. A. Pint, K. L. More, I. G. Wright, and J. L. Smialek, in John Stringer Symposium, Indianapolis, IN, USA, TMS, Warrendale, PA, USA (2001).

23. G. M. Kim, N. M. Yanar, E. N. Hewitt, F. S. Pettit, and G. H. Meier, Scripta Metallurgica et Materialia 46, 489 (2002).

24. V. K. Tolpygo and D. R. Clarke, Acta Materialia 48, 3283 (2000).

25. Y. Zhang, J. A. Haynes, B. A. Pint, I. G. Wright, and W. Y. Lee, Surface \& Coatings Technology 163-164, 19 (2003).

26. P. Nash, M. F. Singleton, and J. L. Murray, in Phase diagrams of binary nickel alloys, P. Nash, ed. (ASM International, Materials Park, OH, 1991).

27. H. E. Evans, International Material Reviews 40, 1 (1995). 